\title{
Relationship between microbial community structures and degradation efficiencies in biological contact process on domestic sewage
}

\author{
Husseini Sulemana ${ }^{1}$, Emmanuel Nkudede $^{1}$, Bo Zhang $^{1 *}$, Anthony Adebayiga Kosiba ${ }^{2}$, Zaina Omary Mochiwa ${ }^{3}$ \\ ${ }^{1}$ School of the Environment and Safety Engineering, Jiangsu University, Zhenjiang 212013, China \\ ${ }^{2}$ EInstitute of Life Sciences, Jiangsu University, Zhenjiang 212013, China \\ ${ }^{3}$ School of Pharmacy, Jiangsu University, Zhenjiang 212013, China
}

\begin{abstract}
In order to ascertain the characteristics of two different biofilm reactors and its efficiency, the influence of $\mathrm{pH}, \mathrm{DO}$ and HRT in the clean-up of COD, NH3-N and TP as well as determining the relationship between microbial community structures and its performance of the two biofilm reactors. This study made use of a biological contact oxidation process system in a small-scale experiment to treat domestic sewage. This contemporary study examined the performance of two different fillers thus, BCF and MBBF in removal of organic pollutants from domestic wastewater as a novel technique of BCOP for sewage treatment. Two self-made biological contact biofilm reactors were used for the experiment: BCR (mounted with BCF) and MBBR (mounted with MBBF). After the biological treatment, the COD concentration of effluent could stay below $350 \mathrm{mg} / \mathrm{L}$. The study analyzed the effects of hydraulic residence time (HRT) on COD, ammonia nitrogen (NH3-N), and total phosphorus (TP) as well as the characteristics of each biofilm filler. The optimal HRT was $12 \mathrm{~h}$; at that time, the experimental results indicated that BCF had higher removal efficiency of chemical oxygen demand, ammonia-nitrogen and total phosphorus at 50\%, $96 \%$, and $86 \%$, respectively. Great contribution was made by the process by means of improving the biodegradability of domestic sewage and reducing sludge emergence via fermentation in the biological reactor.
\end{abstract}

\section{INTRODUCTION}

The biological contact oxidation process (BCOP) is widely applied to eliminate organic matter from domestic sewage [1], industrial organic wastewater [2], and polluted water resources [3]. Also, some engineering methods for river water treatment belong to the BCOP in principle except for the use of a suspended filler $[4,5]$ or ceramic media [6]. However, this research is sentenced on the domestic sewage treatment in conjunction to biological contact oxidation process. In recent years, the biological contact oxidation process to treat wastewater has received increased worldwide attention and popularity. BCOP performance mainly depends on the performance of biological fillers in the sense that, the filter media is one of the main components in the BCOP system besides the aeration and backwash system. Hence, the biological filter media has an obvious impact on the hydraulic characteristics on oxygen-substrate transfer rate [7]. Therefore, the selection of a suitable biological media or filter is crucial in the design of operation and BCOP process, to enable the effluent quality reached the regulated standard [8]. Domestic sewage treatment plant considers the utilization and usage of some particular filter media known to be floating media such as plastic media, polystere pellets, polypropylene, polyurethane pellets and recycled plastic. Specifically, biochemical cotton filler (BCF) was considered to compare its efficiency with moving bed biofilm filler (MBBF) which was made as biofilm carrier and installed in a biofilm reactor as well as the relationship between the microbial community structures and its performance on BCOP. Kent et al. [9] noted that the characterization of filter media is essential to determine their suitability for biofilm growth and attachment, and ammonia removal.

The BCOP reactor consists of equal sized contact oxidation chambers. The differences in pollutant composition and concentration in each chamber leads to generating different kinds of microorganisms, so the design of separated structure in the BCOP reactor is conducive to the biota separation, and could diminish the interspecific competition. The microbial community in each tank could stay in a relatively stable condition, and gradually form a food chain. Therefore, the various pollutants in wastewater could be decreased, step by step, through the metabolism and interaction of microorganisms in the balanced ecosystem. The sludge yield tends to reduced efficiently, due to the predation of high trophic level microbes and the energy loss during biomass conversion. Besides, the biofilms also play an important role on the interception and degradation of suspended solid, so that the wastewater could become

*Corresponding author: tabol@126.com 
clear gradually along the flow direction in the reactor $[10$, 11]. So, biological contact oxidation process (BCOP) is an innovative development of the conventional contact oxidation process, and has distinctive advantages, such as lower running cost, smaller cover space, a lower sludge yield coefficient, and a higher treatment efficiency in small scale domestic sewage treatment. Hence, the Microbial community structure affects the performance of biological contact oxidation process. As such, this study applies intensive small-scale domestic sewage treatment technology in order to achieve the intended motive of the study as per the BCOP system [12].

There have been a gap of relevant studies applying BCOP to treat domestic sewage. Therefore, this study applied BCOP in treating domestic sewage. With the practical engineering aim of reducing the cover space and running cost, modifying the existing processes is primarily geared towards achieving a higher COD removal efficiency. Where the target COD concentration in effluent should be less than $50 \mathrm{mg} / \mathrm{L}$, based on the Jingkou Sewage Treatment discharge standard of Jiangsu Province [13]. Previous research on BCOP has mostly focused on treatment performance and the influence of process parameters. There is little available information on microbial community composition, the relevance between process performance and microbial community in the BCOP system as well as the filler performance as a dependent on the process. Health risks associated with sewage can arise through both direct and indirect contact. The most dangerous component of sewage is excrement, which contains harmful micro-organisms, including bacteria, viruses and parasites as well as chemical pollutants such as COD, ammonia nitrogen, total phosphorous, etc. These micro-organisms and chemical pollutants can be detrimental to human health, causing diseases such as gastroenteritis or hepatitis. So therefore, in this paper, the actual running efficiency of the said technology was studied on the basis of removal capabilities for organic and chemical pollutants in the domestic wastewater, and the feasibility of the technology to treat domestic wastewater was investigated so as to overcome the problem associated with domestic sewage. It may possibly be proven that the microbial diversity and community composition change dynamically in diverse phases to react to the changes in the living environment, so the results might be considered as reference for future research about further optimizing the process parameters and achieving better treatment efficiency. The study results offer a loftier visualization and understanding of the disparity of the comprehensive microbial community in the BCOP reactor from a microbiological perspective.

\section{MATERIALS AND METHODS}

\subsection{Municipal sewage source and its basic quality indicators}

Municipal wastewater/sludge was derived from the primary settling tank of a local sewage treatment plant in Zhenjiang, Jiangsu Province-China, (Jingkou Sewage Treatment Plant) which was used as influent for the experiment. Based on the designed inlet and outlet indexes of JSTP concentration, the main physiognomies of the municipal domestic wastewater/sludge are represented by the indexes and their level of basic concentrations which are as follows: [13].

Table 1. Quality indicators of inlet and outlet indexes

\begin{tabular}{|c|c|c|c|c|c|c|c|}
\hline Indexes & COD & BOD & SS & $\mathrm{NH}_{3}-\mathrm{N}$ & $\mathrm{TN}$ & $\mathrm{TP}$ & $\mathrm{PH}$ \\
\hline $\begin{array}{c}\text { Inlet } \\
\text { concentration }\end{array}$ & 350 & 200 & 200 & 35 & 45 & 3 & $6-9$ \\
\hline $\begin{array}{c}\text { Outlet } \\
\text { concentration }\end{array}$ & 50 & 10 & 10 & $5(8)$ & 15 & 0.5 & $6-9$ \\
\hline
\end{tabular}

\subsection{Filler source and basic characteristics of the constructed biological contact oxidation process}

\subsubsection{Source of the filler}

As depicted by Kent et al., 1996, [9] the selection of appropriate biological contact biofilm media is vital in the design and operation of the sewage treatment process in order to meet required discharge limits. In view of this, media should be resistant to attrition, have appropriate specific weight, high specific surface area, and chemically stable. The biological cotton carrier used for the experiment was obtained from a commercially available online shop known to be Foshan Jiaxiang Aquarium \& Pet Co., Ltd. (Alibaba.com) Guangdong. It was then measured and cut into pieces of square like shapes. The moving bed biofilm carrier was equally purchased online from Yuyao At Machinery Co., Ltd. (Alibaba.com), Ningbo, Zhejiang Province-China. This is a biological suspended filler as a core component of MBBR process which is already molded in a given structure.

\subsubsection{Structural properties of fillers and biofilm formation}

The growth characteristics of biofilms attached on the surface of BCF and MBBF as biofilm carriers were realized based on constructed biological contact oxidation process during the maturing period which consist of original to domestication stage. As per theoretic seen, the BCF and MBBF biofilms are considered matured when they display dark-yellowishbrownish color and dark color respectively on the surface and inner part of the filler, whereas COD and NH3-N removal efficacies reach above $85 \%$ 
concurrently. The growth characteristics of biofilm on BCF and MBBF biofilm carriers are shown in Table 3, which indicated that the biofilms in the reactors matured on day 19th. As at that stage, the thickness/relative density of matured biofilm was $3 \mathrm{~cm}$ and $0.92-0.98 \mathrm{~g} / \mathrm{cm} 3$ in R1 and R2, respectively. Whereas the length of R1 and $\mathrm{R} 2$ was $5 \mathrm{~cm}$ and $10 \mathrm{~mm}$ accordingly. The maturing of the biofilms was boosted during the course of the steady operation period till the completion of the experiment. R1 unveiled much more density of biofilms development as an add-on to BCF. This was possibly ascribed to the enhancement of surface on BCF.

Table 2. The physical growth characteristics of each biofilm

\begin{tabular}{|l|l|l|}
\hline Reactor label & BCR & MBBR \\
\hline Reactor name & BCFR & MBBFR \\
\hline $\begin{array}{l}\text { Biofilm maturing period } \\
\text { (days) }\end{array}$ & 19 & 19 \\
\hline $\begin{array}{l}\text { Thickness/relative density of } \\
\text { matured biofilm }\end{array}$ & $3 \mathrm{~cm}$ & $\begin{array}{l}0.92- \\
0.98 \mathrm{~g} / \mathrm{cm}^{3}\end{array}$ \\
\hline Length & $5 \mathrm{~cm}$ & $10 \mathrm{~mm}$ \\
\hline
\end{tabular}

BCR, MBBR: BCFR biochemical cotton filler reactor, MBBFR moving bed biofilm filler reactor.

\subsection{Water quality indicators and testing methods}

\subsubsection{Parameter analysis method}

At each given HRT's, specific physical parameters such as dissolved oxygen (DO), $\mathrm{pH}$ as well as Temperature were detected where DO probe (JPB-607, Shanghai Jingsheng Scientific instrument Co. Ltd., China) was used to measure the level of DO with a real time determination. A pH probe (pHS-3B, Shanghai Leici instrument Co. Ltd., China) was also used to monitor the $\mathrm{pH}$ of effluent and influent in a systematic manner [14] and Temperature was also measured with an HQ d Portable meter/probe. Chemical parameters specifically, COD, AN, and TP concentrations were analyzed following the Standard Methods for the Examination of Water and Wastewater [15] by the use of spectrophotometer water quality analyzer. The indicators of water quality testing and the testing methods are directly listed in the table below and its corresponding methods.

\subsection{Bacterial Community Analysis}

\subsubsection{Sample collection}

During the experimental period, samples of microbial community structure were periodically collected at each given stage which are as follows: original, domestication and running stages. Seven samples were taken from the surface and interior of both biofilms during the entire process. Raw sludge from original stage, original to domestication stage (BCF and $\mathrm{MBBF}$ ), domestication stage when percentage of wastewater and nutrients were mixed ( $\mathrm{BCF}$ and $\mathrm{MBBF}$ ), running stage (BCF and MBBF). They were expressed by the letters SR1, BCR2, MBBR3, BCR4, MBBR5, BCR6 and MBBR7 respectively. This included the inoculation sludge sample (BCR4 \& MBBR5), and other five activated sludge samples from the bioreactor (SR1, BCR2, MBBR3, BCR6 and MBBR7).

\subsubsection{Microbial sequencing method}

The pretreatment method of the sample is shown in reference [16]. Finally, the biofilm mixture is packed into a sterilized $10 \mathrm{ml}$ centrifuge tube and stored in a $-70^{\circ}$ refrigerator. The DNA sample is then sealed with the sealing film (to avoid the loss or contamination of DNA in transit), and sent to the sequencing company with ice packs in the foam bag. The main process includes DNA extraction, PCR amplification and Illumina PE250 sequencing. The quality control of the original sequence data was carried out by using trimomatic software. The operation classification units were classified according to the standard of $97 \%$ similarity. The operating taxons were classified by the brigadier, and the commonly used biodiversity index was calculated by using the mother software.

\subsubsection{Microbial community diversity}

Fig 2. Shows the microbial based biology based on the Shengxin Tiny Gene analysis report, the PEreds obtained by Miseq sequencing were firstly distinguished from each sample according to barcode. The sequence quality was controlled and filtered, and then spliced according to overlap relationship. The spliced sequences were subjected to quality control and filtration, and finally, the sequence was obtained. Optimization sequence. In relation to the results of OTU cluster analysis, a variety of diversity index analysis (alpha diversity analysis within samples) and the detection of sequencing depth; based on the taxonomic information, statistical analysis of community structure at various classification levels was carried out, and conducted beta between samples diversity analysis. On the basis of the above analysis, a series of in-depth statistical and visual analysis of community structure and phylogeny was also carried out.

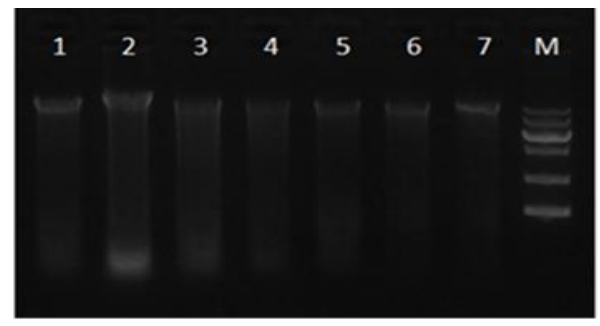

Figure 1. PEreds obtained by Miseq sequencing from each sample according to barcode.

\subsection{Experimental set-up procedure}

Two laboratory-scale biological contact biofilm reactors (BCBR) were made of acrylic for experimental setup and 
are shown in Fig. 1. The height of the reactor was $54.5 \mathrm{~cm}$ serving as the main reaction district, $30.8 \mathrm{~cm}$ inner diameter, with a working volume of $41 \mathrm{~L}$ and cylindrical in shape. Each reactor was packed with $\mathrm{MBBF}$ in a square like shape and $\mathrm{BCF}$ in a circular shape. Each filler type was kept beneath and above the steadying trapper in each biofilm reactor. The goal of a reactor designed in such a way was to ensure enough contact between the pollutants and the microorganisms. The experiment comprised of three different stages from the onset which are Original stage, Domestication stage and Running stage. Where wastewater and sludge were decanted into the biofilm reactors as and when the need arises. Also, oxygen was pumped into the biological reactors by aeration pump, while the flow rates were precisely regulated by the airflow meter. The aeration produced served as a source of energy booster to the biofilm microbes in the wastewater [17]. Air diffuser was used in the biofilm reactor in order to prevent the biomass washout. Uniform aeration is supportive to safeguard the biofilm. The basic operation process of the test is summarized in combination with the test diagrams below.
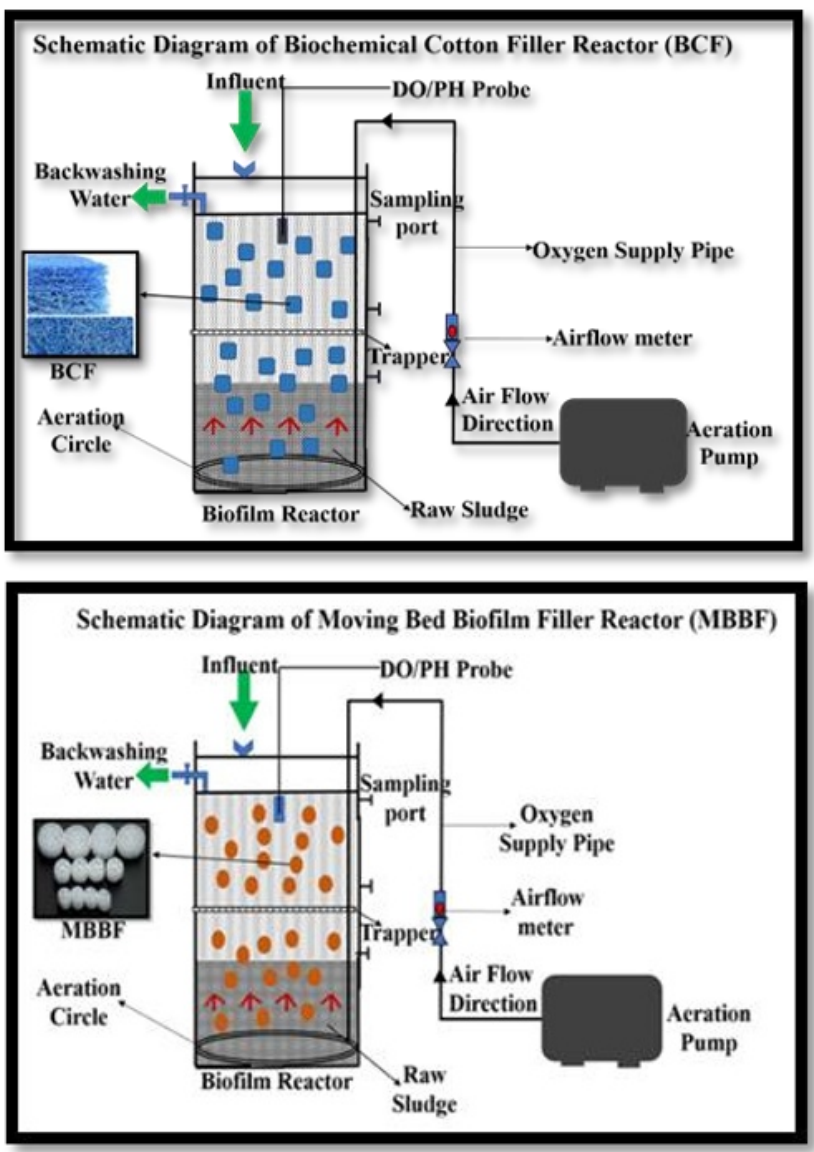

Figure 2. Experimental schematic diagrams of the setup indicating the biological contact biofilm reactor (BCR and MBBR)

\section{RESULTS AND DISCUSSION}

\subsection{Overview description of test results}

This study is known to be that of Biological contact oxidation process which is a mixed technology of biological filter process and activated sludge technology. It possess both merits of activated sludge process and bio-film process, and also has characteristics of small size, simple management, enduring impact load, efficiency and stability treatment, which make it widely to be used in treating surfactants wastewater, oily wastewater, domestic sewage, industrial wastewater and so on[18-21]. In this paper, two pilot-scale test of selfdeveloped integration Biological Contact Oxidation reactors for domestic sewage treatment was carried out as well as assessment of biofilm performance. The two (2) biological contact reactors were steadily kept functioning (original $\rightarrow$ domestication $\rightarrow$ running stage) for over 60 days with comparatively stable conditions as at the time when the biofilms were considered matured. These comparatively stable conditions consisted of the following physical index with different range at a given HRT (8hrs, 10hrs \& 12hrs); DO (1-2, 2-3 \& 3-4mg/L), $\mathrm{pH}(6.5,7.5 \& 8.5 \mathrm{mg} / \mathrm{L})$, and temperature $\left(25.0-27.0^{\circ} \mathrm{C}\right)$. Figure 1 and 2, show the COD and its removal rate of $\mathrm{pH}(6.00-7.50 \mathrm{mg} / \mathrm{L})$ and COD and its removal rate of $\mathrm{pH}(6.00-7.00 \mathrm{mg} / \mathrm{L})$ according to the changes in water quality parameters during the intermediate process of the two biofilm reactors (BCR and MBBR).

\subsubsection{Changes in water quality parameters during the intermediate process}

The differences in pollutant composition and concentration in each bioreactor leads to generating different kinds of microorganisms, so the design of separated structure in the MLCOP reactor is conducive to the biota separation, and could diminish the interspecific competition. The microbial community in each bioreactor could stay in a relatively stable condition, and gradually form a food chain. Therefore, the various pollutants in wastewater could be decreased, step by step, through the metabolism and interaction of microorganisms in the balanced ecosystem. The sludge yield was reduced efficiently, due to the predation of high trophic level microbes and the energy loss during biomass conversion. Besides, the biofilms also play an important role on the interception and degradation of suspended solid, so that the wastewater could become clear gradually along the flow direction in the reactor $[9$, 22]. 


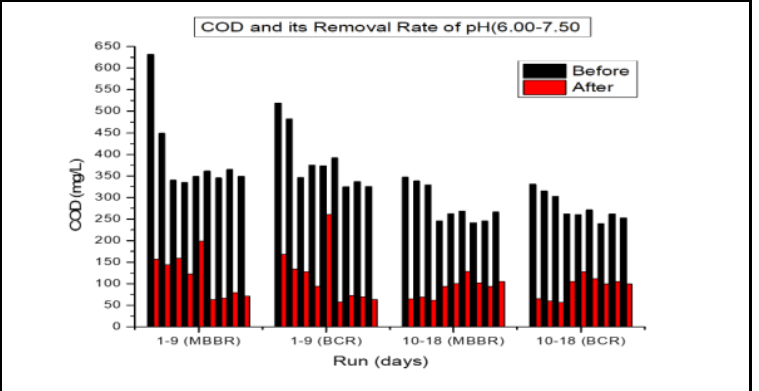

Figure 3. $\mathrm{COD}$ and its removal rate of $\mathrm{BCR}$ and $\mathrm{MBBR}$ as of original stage

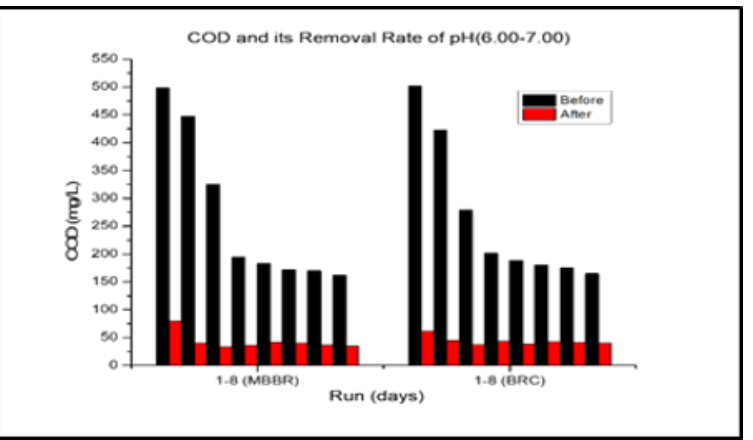

Figure 4. $C O D$ and its removal rate of $B C R$ and $M B B R$ as of domestication stage

Subsequently, the effectiveness of pollutant elimination by the biofilm reactors fixed with $\mathrm{BC}$ and MBB fillers was measured, the following three basic operation index $\mathrm{COD}, \mathrm{NH}_{3}-\mathrm{N}$ and TP for monitoring the water quality were also studied. These three parameters were critically observed and monitored on daily basis, as the biofilm reactors continuously run.

\subsubsection{Biofilm growth at different stages on the packing}

Table 3. Summarizes the characteristics and pollutant removal efficiencies of different bioflm carriers used for wastewater treatment.

\begin{tabular}{|l|l|l|l|}
\hline No. & Characteristics & MBBF & BCF \\
\hline 1 & Colour & $\begin{array}{l}\text { Exhibited dark } \\
\text { brownish colour }\end{array}$ & $\begin{array}{l}\text { Exhibited } \\
\text { dark colour }\end{array}$ \\
\hline 2 & Weakness & $\begin{array}{l}\text { Still strong till the } \\
\text { end of the } \\
\text { experiment }\end{array}$ & $\begin{array}{l}\text { Looks } \\
\text { tattered at the } \\
\text { end of the } \\
\text { experiment } \\
\text { that's when } \\
\text { forcibly } \\
\text { stretched }\end{array}$ \\
\hline 3 & Resilience & $\begin{array}{l}\text { Still strong when } \\
\text { stretched }\end{array}$ & $\begin{array}{l}\text { Easily get } \\
\text { pull to pieces } \\
\text { when } \\
\text { stretched }\end{array}$ \\
\hline 4 & $\begin{array}{l}\text { Stress } \\
\text { persistence }\end{array}$ & $\begin{array}{l}\text { Stress free due to } \\
\text { its impact strength } \\
\text { according to how } \\
\text { its designed }\end{array}$ & $\begin{array}{l}\text { Looks less } \\
\text { resilience due } \\
\text { to its spongy } \\
\text { nature }\end{array}$ \\
\hline
\end{tabular}

\subsection{Domestic waste water treatment results based on degradation principle}

\subsubsection{COD Removal}

The monitored removal efficacy of COD was as a results of variation with time throughout the operational phase which is the running stage of each biofilm reactor as shown in Fig. 3 and 4. When the HRT sequentially increased from 0 to $8 \mathrm{~h}, 10 \mathrm{~h}$ and $12 \mathrm{~h}$, the removal efficacy of COD in BCR rapidly increased from 0 to $51 \%$ while MBBR also rapidly increased from 0 to $45 \%$.

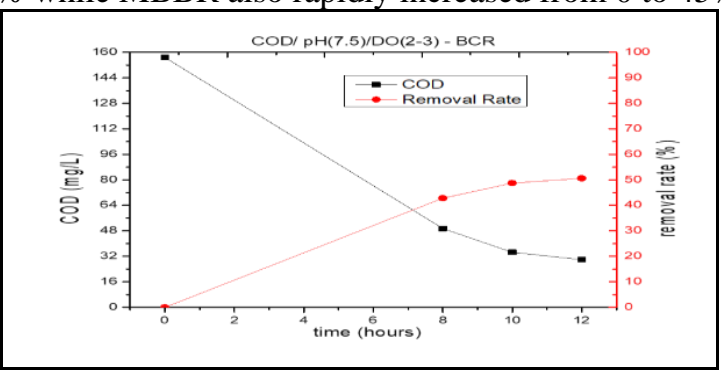

Figure 5. COD removal efficiency of biofilm reactor installed with BCF

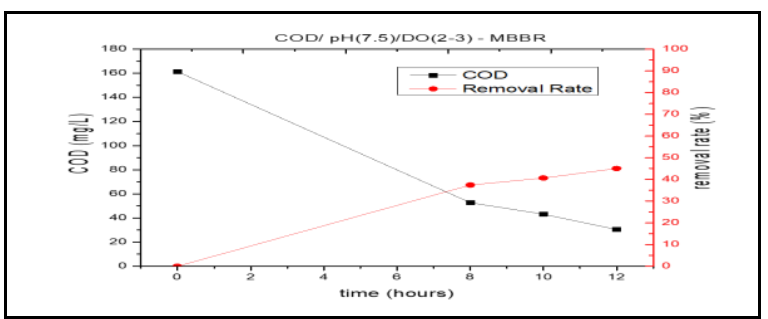

Figure 6. COD removal efficiency of biofilm reactor installed with MBBF

Also, when the treatment time further increased from 17 to 34 days, the removal efficiency of COD in both BCR and MBBR gradually augment and respectively altered a little from $51 \%$ and $45 \%$ to $53 \%$. Perhaps this could be as a results of when biofilm microbe's growth period was below 17 days, the biofilm thickness and density were low which could be due to low reproduction rate. However, the microbial cells as at this given period aren't adequately matured so as to captivate, champion and cut down more organic pollutants which will lead to somewhat low elimination efficiency of COD. As the treatment period upsurges, the biofilms get ample time for their bioactivities which pave way for them to consume and decompose extra organic contaminant leading to high elimination efficiency of COD. During the steadily operational/running stage period, the average removal efficacy of COD in BCR, average COD of effluent concentration and average COD of influent were $50 \%, 37.07 \mathrm{mg} / \mathrm{L}$ and $159.08 \mathrm{mg} / \mathrm{L}$, respectively, which are in accordance with the result of biofilm formation test. On the other hand, the average removal efficacy of COD in MBBR, and average $\mathrm{COD}$ of effluent concentration and average COD of influent were $46 \%, 33.99 \mathrm{mg} / \mathrm{L}$ and 161.75 $\mathrm{mg} / \mathrm{L}$, respectively. The difference of the average COD removal efficiency between BCR and MBBR was $4 \%$. 
This could therefore be recognized to the point that BCR enhanced more biofilm formation and pollutant degradation

\subsubsection{NH3-N Removal}

With time disparities in the biological contact biofilm reactors Figure 5 and 6 depicts the removal efficiency of NH3-N. As it can be seen from the figure below, when the treatment period further gets to the latter part of the experiment, the removal efficiency of NH3-N in MBBR swiftly increased from $0 \%$ to $92 \%$, while BCR NH3-N removal rate also increased hastily from $0 \%$ to $96 \%$.

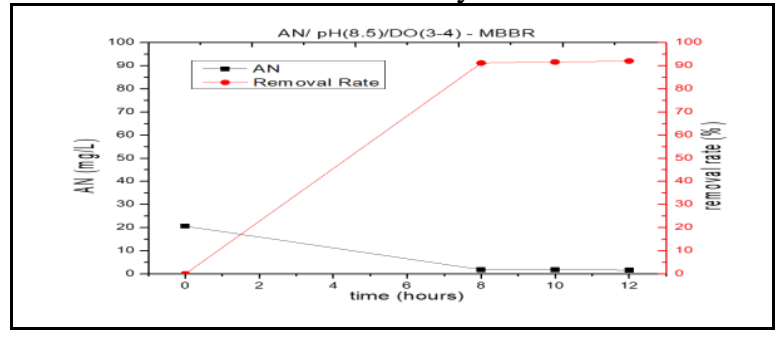

Figure 7. AN removal efficiency of biofilm reactor installed with MBBF

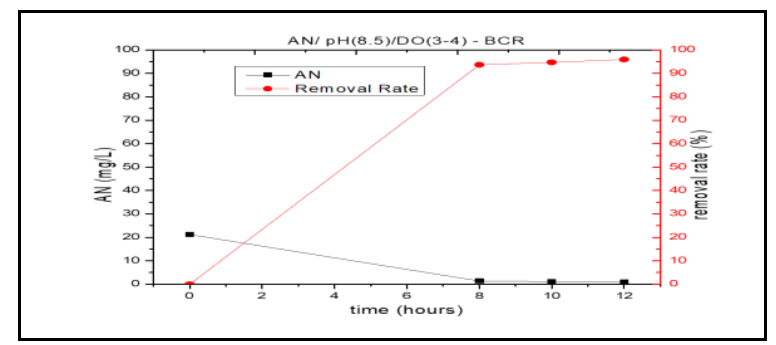

Figure 8. AN removal efficiency of biofilm reactor installed with $\mathrm{BCF}$

Moreover, when the treatment phase commenced from the early running stage as at the 20 days of the entire stages, the removal efficiency of NH3-N in MBBR sluggishly increased and fluctuated whereas the BCR removal efficiency of NH3-N likewise increased slowly and fluctuated. This possibly will be as a result of the immature cells of the autotrophic nitrifying bacteria (AOB) and nitrite-oxidizing bacteria (NOB) within this phase; hence, the capacity to degrade more NH3-N in the domestic wastewater is repressed leading relatively low removal efficiency of ammonia-nitrogen. However, as the wastewater treatment period upsurges from 20 to 36 days, the nitrification bacteria tends to be extremely matured and energetic. This then leads to more breakdown of ammonia-nitrogen by the nitrification bacteria leading high removal efficiency. The average efficiency of NH3-N removal for BCR installed with BCF was $93 \%$ with corresponding $22.25 \mathrm{mg} / \mathrm{L}$ of average effluent concentration and average influent concentration of $2.094 \mathrm{mg} / \mathrm{L}$. This revealed optimum performance of BCR over MBBR. In view of this, it can be realized according to the different removal aptitudes of the two reactors. During the steady operational/running period, the optimal removal efficiency of BCR was $96 \%$, whereas maximum NH3-N removal efficiency of MBBR was determined at $92 \%$ with difference of $4 \%$ between the two reactors. This could be as a results of boosted surface of BCF which led to more favourable conditions for biofilm growth and add-on.

\subsubsection{Total phosphorus (TP) removal}

Figure 7 and 8 displays the TP removal efficiency in the biofilm reactors in diverse treatment HRT's at a given $\mathrm{pH}$ and DO. With reference to the operational/running phase which commenced from the 20th day, the removal efficiency of TP in BCR quickly increased from 0 to $86 \%$, while TP removal rate in MBBR also increased from 0 to $78 \%$. Furthermore, when the treatment time increased from different HRT's of $8 \mathrm{hr}$ to $12 \mathrm{hrs}$, the removal efficiency of TP in BCR fluctuated between from 46 and $86 \%$ whereas the MBBR removal efficiency of TP increased slowly and fluctuated a little between 27 to $78 \%$.

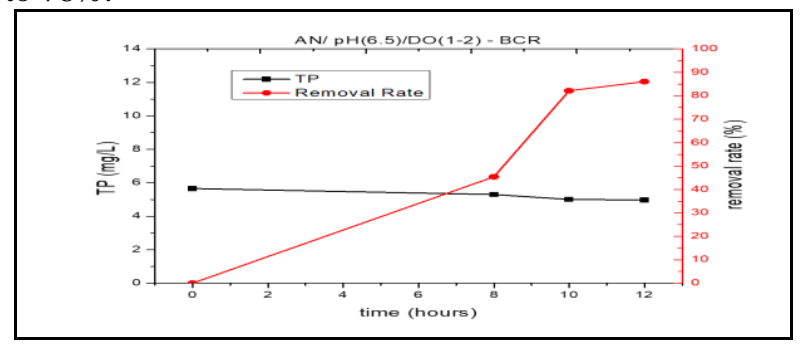

Figure 9. TP removal efficiency of biofilm reactor installed with BCF

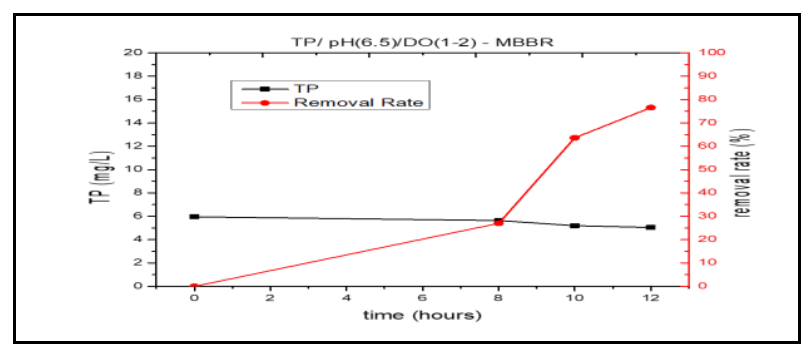

Figure 10. TP removal efficiency of biofilm reactor installed with MBBR

This phenomenon may have occurred since the treatment period was at the early stages of the process, hence the reproduction of biofilms and attachment growth will be at under-development stage; this then restricts the ability of polyphosphate bacteria to absorb and break down TP at a high rate. Furthermore, as the polyphosphate bacterial stabilizes and develops, the TP removal efficiency also tends to improves and exhibit a relatively high rate. However, the TP removal efficiency is comparatively lower than the other monitored chemical pollutant (COD and NH3-N). This was perhaps due to aside biofilm formation time, other factors such as HRT, DO, pH and temperature also influence the removal rate of TP.

\section{CONCLUSIONS}

In this latest study, a BCOP system was used to ascertain the feasibility and efficacy of BCF and MBBF as biofilm 
carriers in small scale domestic sewage treatment. The outcomes of the domestic wastewater treatment as per the process performance revealed that BCFR could efficiently degrade the refractory organic substances in domestic sewage than MBBF. The outcomes of the domestic wastewater treatment revealed that $\mathrm{BCF}$ was more efficient for pollutant degradation than MBBF. The BCF installed in BCFR had higher removal efficiency of COD, NH3-N and TP in the domestic sewage treatment than MBBF installed in MBBFR. Herein, after BCOP treatment, the total COD, NH3-N, and TP removal rate increased to the maximum at the optimal HRT of $12 \mathrm{~h}$. Notably, all the pollutants indices of the effluent measured corroborated with the Jingkou sewage discharge standard of Jiangsu province. This method further significantly enhanced wastewater biodegradability, reduced excess sludge production during the operational period, and was very costeffective. Under persistent treatment of this study, the relationship between microbial community compositions and degradation efficiency in biological contact process on domestic sewage as well as the characteristics of the said fillers significantly shifted in different stages, signifying that the microbial community dynamically and submissively transform to react to changes in the living environment at a dominant level. This study proved that the BCOP system is a remarkable technological choice that declines the COD concentration of domestic wastewater. It is associated with low maintenance requirements, a simple structure, and needs only a lesser cover space. With regards to these advantages, this method could serve as an effective subsequent biological treatment process to further lower the COD concentration of domestic wastewater, with wide-ranging positive economic and social benefits. The outcomes of this study may be used as a backing for impending engineering projects in small scale domestic sewage treatment.

\section{REFERENCE:}

1. X.K. Li, R.X. Huang, L.L. Bao, C.H. Shao, J. Zhang. Simultaneous phosphorus and nitrogen removal in a continuous-flow two-sludge system. J. of Env. Sci., 2006, 18(1):52-57

2. C.K. Chen, S.L. Lo. Treatment of slaughterhouse wastewater using an activated sludge/contact aeration process. Wat. Sci \& Tech, 2003, 47(12): 285-292

3. Y.T. Xiao, M. Wu, H. Liu, J.H. Xu. Removal of NO4+-N from polluted water resources by bioremediation of biofilm process with elastic packing and micropore aerator. Env. Sci., 2001, 22(3):40-43 (in Chinese)

4. X.J Wang, S.Q Xia, Q.X. Zhang, W.M. Li, S.Y. Li. Treatment of the branch water of Suzhou River by using suspended filler moving-bed. Tech. and Equi. for Env. Poll. Con, 2002, 3(1): 27-30 (in Chinese)

5. R.C Wang, X.H. Wen, Y.Q. Jing, Y. Qian. Remediation of polluted river water by using a suspended carrier biofilm reactor. Env-men. Sci, 2004, 25(Suppl): 67-69 (in Chinese)

6. Y.S. Park, J.H. Moon, D.S Kim, K.H. Ahn. Treatment of a polluted stream by a fixed-bed biofilm reactor with sludge discharger and backwashing system. Che. Eng. J., 2004, 99: 265271

7. L.M. Espinosa., and T. Stephenson. (1999). "Review of biological aerated filters (BAFs) for wastewater treatment.” Env. Eng. Sci., 16(3): pp201.

8. H. Tan. (2007). "An evaluation of biological aerated filtration for wastewater treatment through pilot and laboratory scale experiments." Ths. of Mas. of Sci.. Queen's University, Kingston, Ontoria, Canada

9. T.D. Kent., C.S.B Fitzpatrick., and S.C Williams. (1996). "Testing of biological aerated filter (BAF) media.” Wat. Res., 34(3-4): pp363-370.

10. T.L. Zheng, P. Li,; Q.H Wang.; X.S Li, Ai, H.Y. Pilot-scale experiments on brewery wastewater treatment and sludge reduction based on food chain predation. Desalin. Wat. Treat. 2014, 55, 1-10.

11. Li, P.; Zheng, T.L.; Wang, Q.H.; Yang, S.; Liu, S.; Li, L.J.; Huang, P.K. Treatment of real highconcentration dyeing wastewater using a coagulation-hydrolysis acidification-multilevel contact oxidation system. Environ. Prog. Sust.. 2015, 34, 339-345.

12. Miura, Y.; Hiraiwa, M.N.; Itonaga, T.; Watanabe, Y. Bacterial community structures in MBRs treating municipal wastewater: Relationship between community stability and reactor performance. Wat. Res. 2007, 41, 627-637.

13. GB18918-2002. Jingkou Sewage Treatment Plant of Jiangsu Province, Zhenjiang Water Service Group, July 1st 2009.: Urb. Sew. Reg and Util.: Jiangsu Province, 2009

14. R-J Zhao et al (2018) Property of filler-loaded magnetic ferrite from plastic waste bottle used to treat municipal domestic sewage. Env. Tech. 39(12):1607-1613

15. APHA, Standards Methods for the Examination of Water and Wastewater, 21st ed., Amer. Pub. Hea. Ass., Wash, DC, 2005.

16. M. Wagner, A. Loy, R. Nogueira, et al. Microbial community composition and function in wastewater treatment plants [J]. Antonie Van Leeuwenhoek, 2002, 81(1-4):665-680.

17. X-M. Zhan, M. Rodgers, O'Reilly E (2006) Biofilm growth and characteristics in an alternating pumped sequencing batch biofilm reactor (APSBBR). Wat. Res 40(4):817-825

18. D. Yue, C. Sheng, S. Dezhi, Short-Cut Nitrification of Landfill Leachate by Aerobic Moving-Bed Biofilm Reactor, Env. Sci, Vol.28, No.5, 2007, pp.10391043.

19. C. Hongbin, L. Yuping, C. Yanli, Y. Zhang, Treatment of Aniline by Contact Biologieal 
Oxidation on the Biofflm, ACTA Scie. Circum, Vol.24, No.1, 2004, pp.33-37.

20. J. Zhou, Z. Li, L. Tengrui, J. Wenchao, Y. Tao, Denitrification on Integrated Multistage Biofilm Reactor for High-Nitrogenm Unicipal Wastewater Treatment, ACTA Sci. Cir., Vol.27, No.11, 2007, pp.1804-1808.

21. X. Wensheng, W. Wenguo, Sacle-Producing Test for Treating Domestic Wastewater by Membrane Bioreactor, Tech. of Wat. Treat., Vol.32, No.11, 2006, pp.71-73.

22. S.B. He., G. Xue., and H.N Kong. (2007). "The performance of BAF by using natural zeolite as filter media under conditions of low temperature and ammonium shock load." J. of Haz. Mat., 143: pp291-295. 